\title{
Bedaya Duradasih, Sebuah Ekspresi Budaya pada Masa Sunan Pakubuwana III-IV di Keraton Surakarta
}

\author{
Indah Nuraini ${ }^{1}$ (Penulis Korespondensi) \\ Jurusan Tari, Fakultas Seni Pertunjukan, Institut Seni Indonesia Yogyakarta \\ Supriyanti \\ Jurusan Tari, Fakultas Seni Pertunjukan, Institut Seni Indonesia Yogyakarta
}

\begin{abstract}
Bedaya Duradasih: A Cultural Expression During the time of Sunan Pakubuwana III-IV in the Surakarta Palace. Bedaya Duradasih is a form of bedaya dance created at the Surakarta Palace. Its creator was Sunan Pakubuwana IV who at that time, still had the title of Kanjeng Gusti Pangeran Adipati Anom. Sunan Pakubuwana IV was a king who had a very significant artistic spirit, so it cannot be denied that artistic and cultural life was very flourishing during his reign. Bedaya Duradasih was one of the cultural expressions at that time. The created expression was inspired by the mood of being infatuated/falling in love with the Madurese princess. Looking at the words Duradasih and Madura can be connected with several opinions regarding the meaning of the word Duradasih. It is said that Duradasih derived from the words Dura and dasih, which mean a woman from Madura. Then it is also mentioned from the words Dara and dasih, which means girl/virgin who brings happiness. Furthermore, it is interpreted from the words Dora and dasih, which means lying for political interests at that time, which ended up with a love affair. From these descriptions, it can be concluded that Bedaya Duradasih reflects one of the cultural expressions.
\end{abstract}

Keywords: bedaya; Surakarta; expression

\section{Pendahuluan}

Keraton Surakarta didirikan oleh Ingkang Sinuhun Kanjeng Sunan Pakubuwana II. yaitu pada tahun 1745. Diperingati dengan candrasengkala "Kombuling Pudya Kapyarseng Nata" warsa Jawi angka 1670. Berdiri di atas tanah di Desa Sala. Maksud didirikan Keraton, kecuali untuk pusat pemerintahan pada waktu itu, juga menjadi sumber kebudayaan Jawa (Pakoe Boewono XII. 1992. "Seminar Kebudayaan Posisi Kraton di Tengah Perubahan Zaman”). Pada masa rajaraja berkuasa, raja adalah pusat segalanya; raja dengan kekuasaannya menentukan segala sesuatunya. Demikian dengan kehidupan kesenian istana yang merupakan salah satu unsur penegak kewibaan raja. Mereka berpendirian bahwa kesenian, khususnya tari dan karawitan, merupakan pusaka atribut kerajaan yang menjadi kebanggaan tiap-tiap raja dengan segenap kerabat dan rakyatnya (Edi Sedyawati, 1981: 27). Bedaya merupakan salah satu alat kebesaran raja yang temasuk di dalam pusaka kerajaan, serta merupakan sebagian dari kekayaan kerajaan yang turut memberikan kontribusi dalam mengkultuskan kemegahan raja (A.M. Hermien Kusmayati, 1988:29).

Dari sepotong uraian di atas dapat telihat betapa bedaya memang dibentuk untuk difungsikan sedemikian rupa demi memperkokoh tegaknya kewibawaan raja. Secara historis, sesudah berlangsungnya

\footnotetext{
$1 \quad$ Alamat korespondensi: Jurusan Tari, Fakultas Seni Pertunjukan, ISI Yogyakarta, Jalan Parangtritis km.6,5 Sewon, Bantul, Daerah Istimewa Yogyakarta. Email: nurainiindah661@gmail.com, supriyantitari@gmail. com; HP.: 087850043027, 08121561257.
} 
Perjanjian Giyanti pada tahun 1755, maka Kerajaan Mataram terpecah menjadi dua kerajaan, yaitu Kasunanan Surakarta dan Kasultanan Yogyakarta. Dari masing-masing kerajaan tersebut kemudian mempunyai sebuah Kadipaten yaitu Mangkunegaran untuk Kasunanan Surakarta, dan Pakualaman untuk Kasultanan Yogyakarta. Seperti di dalam Kasunanan Surakarta ataupun di dalam Kasultanan Yogyakarta, dari masing-masing Kadipaten tersebut juga melangsungkan aktivitasnya dalam hal budaya, terutama tari, misalnya bedaya dan srimpi.

Di Keraton Kasunanan Surakarta terdapat beberapa macam bentuk tari bedaya, antara lain Bedaya Ela-ela, Bedaya Sukaharja, Bedaya Mangunharja, Bedaya Kabor, Bedaya Endol-endol, Bedaya Duradasih, Bedaya Tejanata, Bedaya Ketawang, dan Bedaya Pangkur (Martopangrawit, 1975: 3-4). Pada umumnya pemberian nama atas tari bedaya tersebut diambilkan dari nama gending yang mengiringinya. Seperti halnya dengan nama Bedaya Duradasih, karena diiringi dengan gending Duradasih laras slendro pathet manyura, berdasarkan lagu sekar ageng Duradasih. Adapun gending serta tari Bedaya Duradasih ini adalah buah ciptaan dari Sunan Pakubuwana IV di Keraton Surakarta ketika masih bergelar Kangjeng Gusti Pangeran Adipati Anom, yaitu pada hari Sabtu menjelang a khad 30 Dulkangidah Jimakir 1707 sinengkalan Wasiteng Tawang Titihan Gusti (K.R.M.H. Yosodipuro, Surakarta, wawancara 5-5-1984). Dalam menciptakan tari ataupun gending ini diilhami oleh suasana hati Kanjeng Gusti Pangeran Adipati Anom yang pada saat itu sedang jatuh cinta kepada seorang putri dari Madura, bernama Raden Ajeng Handaya, yaitu puteri Raden Adipati Cakraningrat dari Pamekasan Madura.

Boleh dikatakan bahwa karena sedemikian cintanya terhadap putri darah Madura itu, maka terwujudlah ungkapan jiwa atau perasaan tesebut ke dalam bentuk karya seni tari, yaitu Bedaya Duradasih. Hal ini seperti pendapat yang telah diungkapkan oleh Soedarsono, bahwa tari merupakan ungkapan ekspresi atau ungkapan jiwa manusia yang diwujudkan melalui gerakgerak yang ritmis dan indah (Soedarsono, 1972: 4). Kecintaan Kanjeng Gusti Pangeran Adipati Anon kepada putri darah Madura itu disebutkan pula di dalam sebuah buku tentang kehidupan Keraton Surakarta tahun 1830-1939. Dikatakan bahwa diawali dari Sunan Pakubuwana III, permaisuri raja-raja Surakarta berasal dari Madura, kemudian pola kehidupan ini diikuti oleh putranya, yaitu Sunan Pakubuwana IV. Bahkan, ketika masih sebagai putra mahkota, istri utamanya berasal dari Madura, dan setelah dinobatkan menjadi raja serta bergelar sebagai Sunan Pakubuwana IV, mengambil permaisuri dari darah Madura pula, yaitu adik dari Raden Ajeng Handaya yang bernama Ratu Kencana. Hal ini dilaksanakan karena setelah mempunyai putra pertama Raden Ajeng Handaya wafat (Darsiti Soeratman, 1989: 50).

Hubungan dengan Madura telah ada sejak zaman Mataram, yaitu pada saat Sultan Agung dapat menguasai Pulau Madura (1624). Untuk kepentingan politik Amangkurat Seda Tegalarum memberikan putrinya kepada Pangeran Cakraningrat, putra Panembahan Seda Kamal. Di Madura, putri ini dikenal sebagai Ratu Ayunan. Amangkurat IV juga memberikan putrinya untuk dijadikan istri Pangeran Adipati Cakraningrat, putra Panembahan Cakraningrat. Kebiasaan memberikan pengantin wanita kepada penguasa di Madura tersebut berubah ketika Kerajaan Mataram pecah menjadi dua (1755). Beberapa raja Surakarta mengambil putri-putri Madura untuk permaisurinya, dan langkah yang diambil ini erat hubungannya dengan perubahan kedudukan penguasapenguasa di Madura. Menurut perjanjian 1705 dan 1749, Madura jatuh ke tangan VOC dan selanjutnya menjadi daerah milik pemerintah Hindia Belanda. Oleh pemerintah kolonial ini status penguasa pribumi di Sumenep, Pamekasan, dan Bangkalan dibuat sejajar dengan kedudukan raja-raja Surakarta 
dan Ngayogyakarta. Dalam kenyataannya, pemerintah kolonial menganggap para penguasa pribumi di Madura itu hanya sebagai bupati (Darsiti Soeratman, 1989: 52).

Seperti yang telah diuraikan di atas bahwa pada umumnya nama dari tari bedaya di Surakarta itu mengambil dari nama gending yang mengiringinya. Tidak seperti halnya dengan tari bedaya di Yogyakarta, yang biasanya mengambil nama dari isi ceriteranya, sebab pada umumnya tari bedaya di Yogyakarta membawakan suatu ceritera. Oleh karena itu penulis berkeinginan untuk mengetahui apakah yang melatar belakangi terciptanya nama Duradasih tersebut sehingga menjadi judul dari sebuah tarian bedaya di kraton Surakarta pada masa pemerintahan Sunan Pakubuwana III-IV, yang masih mampu hidup di tengah-tengah masyarakat masa kini. Secara simbolis dapat dilihat melalui bentuk koreografinya, maka tari bedaya Duradasih tersebut dapat diinterpretasikan merupakan gambaran percintaan. Hal ini dapat dilihat dari beberapa ragam gerak tarinya dan juga pola lantai yang terdapat di dalamnya. Dengan melihat dari beberapa ragam gerak tari serta pola lantai tersebut dapat diperkirakan pula bahwa ada hubungannya dengan suatu peristiwa tertentu. Misalnya seperti penggambaran sebuah perjalanan dengan menggunakan perahu dayung melalui sebuah sungai besar.

Oleh karena itu, sesuai dengan latar belakang yaitu tentang percintaannya Kanjeng Gusti Pangeran Adipati Anom dengan seorang puteri dari Madura, maka hal tersebut di atas sangat dimungkinkan. Dengan dasar bahwa hubungan lalu lintas antara kraton Surakarta dengan Madura pada waktu itu sangat besar kemungkinannya dicapai dengan melalui sungai, sehingga boleh dikatakan bahwa salah satu gerak-gerak tari menggambarkan seolaholah menirukan gerak orang yang sedang mendayung perahu. Hal ini dapat diperkirakan sebagai penggambaran pengalaman perjalanan Kanjeng Gusti Pangeran Adipati Anom dari kraton Surakarta untuk menemui kekasihnya di Madura. Dengan demikian merupakan suatu simbol hubungan cinta kasih serta ikatan persaudaraan antara kraton Surakarta dengan kadipaten Madura.

\section{Latar Belakang Lahirnya Bedaya Duradasih}

Telah disebutkan di depan bahwa hubungan dengan Madura sejak zaman Mataram, yaitu pada saat Sultan Agung dapat menguasai pulau Madura (1624). Ketika Ingkang Sinuhun Kanjeng Susuhunan Paku Buwana ke III memerintah di keraton Surakarta Hadiningrat, putera baginda yang dicita-citakan untuk menggantikan baginda yaitu bernama Kanjeng Gusti Pangeran Adipati Anom. Namun sayang sekali pada saat diadakan penelitian ini belum ditemukan catatan siapa nama Kanjeng Gusti Pangeran Adipati Anom itu pada masa kanak-kanak. Hanya saja diterangkan bahwa putera baginda itu dilahirkan pada hari kamis wage jam 10.00 (pagi) pada tanggal 18 Rabiulawal tahun Je, 1694, Wuku Watu Gunung, Windu Sengara (Sunar Tri Suyanto. 1985. Ingkang Sinuhun Kanjeng Susuhunan Paku Buwana IV Beserta Ajaran-ajarannya. p, 9).

Nama Duradasih ini tercipta karena Kanjeng Gusti Pangeran Adipati Anom mempunyai kisah yang menarik bagaikan sebuah mimpi. Di dalam buku Bausastra Jawa Indonesia dikatakan bahwa arti Duradasih itu adalah sama dengan terlaksana (terjadi) seperti mimpi (S.Prawiroatmojo. 1988. Bausastra Jawa Indonesia. p. 98).

Kisah menarik yang dialami Kanjeng Gusti Pangeran Adipati Anom tersebut diawali dengan Ingkang Sinuhun Kanjeng Sunan Paku Buwana III bertitah agar Raden Ajeng Handaya, puteri Adipati Cakraningrat dari Pamekasan Madura supaya mengabdi ke keraton Surakarta. Sebagai abdi dalem, Raden Ajeng Handaya dididik dengan segala macam peraturan dan adat istiadat keraton Surakarta. Menurut rencana akan dijodohkan dengan Kanjeng Pangeran Adipati Anom, dengan maksud untuk melanjutkan hubungan 
kekeluargaan dengan trah dan keturunan Madura. Untuk melaksanakan kehendak tersebut, maka dipanggilah Kanjeng Pangeran Adipati Anom serta Raden Ajeng Handoyo untuk menghadap Sinuhun Paku Biwana III. Kemudian Kanjeng Sinuhun Paku Buwana III bertitah Agar Kanjeng Pangeran Adipati Anon mau menikah dengan Raden Ajeng Handaya. Namun perintah tersebut ditolak oleh Kanjeng Gusti Pangeran Adipati Anom, karena beliau tidak tertarik dan tidak berkenan pada Raden Ajeng Handaya yang wajahnya kurang menarik bagi beliau, sebab disamping berwajah jelek, berkulit hitam dan suaranya pun seperti seorang laki-laki. Hal tersebut membuat hati Sunan Paku Buwana III kecewa dan bersedih, namun tetap berusaha untuk terlaksananya maksud baik tersebut. Kemudian Kanjeng Sinuhun Sunan Paku Buwana III pergi bertapa untuk memohon kepada Tuhan agar Raden Ajeng Handaya dapat berubah wajahnya menjadi seorang puteri yang cantik, sehingga Kanjeng Pangeran Adipati Anom akan menjadi tertarik kepada Raden Ajeng Handaya.

Oleh karena sangat kuat permohonannya, sehingga mendapatkan suatu wangsit, supaya Raden Ajeng Handaya diwiradati (diupayakan), dengan harus melakukan ibadah puasa serta memandikan puteri tersebut dengan air bunga pada setiap pagi hari sebelum mata hari terbit. Adapun syarat orang yang memandikan Raden Ajeng Handaya adalah seorang yang sudah tua usianya dan berpangkat sebagai Nyai Mas Tumenggung serta yang kuat dalam berpuasa. Sedangkan yang dipakai untuk memandikan (bak Mandinya) yang terbuat dari bokor kencana, selain hal tersebut, disamping itu Raden Handaya harus minum ramuan jamu di setiap pagi hari.

Setelah beberapa waktu melakukan kewajiban tersebut, maka pada suatu ketika terjadilah keajaiban yang sangat menggembirakan bagi Kanjeng Sunan Paku Buwana III, sebab puteri dari Madura itu betul-betul berubah menjadi seorang puteri yang sangat cantik jelita. Dengan peristiwa itu kemudian Kanjeng Sunan Paku Buwana III memanggil kembali puteranda yaitu Kanjeng Gusti Pangeran Adipati Anom serta Raden Ajeng Handaya puteri dari Madura tersebut. Setelah keduanya menghadap, sekali lagi beliau bertitah seperti pada waktu yang lalu yaitu agar puteranda mau menikah dengan Raden Handaya puteri Adipati Cakraningrat dari Madura tersebut. Tetapi Kanjeng Gusti Pangeran Adipati Anom tetap menolak titah ayahandanya itu, sebab beliau diam-diam telah tertarik dan jatuh cinta dengan puteri yang berada di hadapannya itu (yang sebenarnya adalah juga Raden Ajeng Handaya). Karena memang Kanjeng Sunan Paku Buwana III sengaja telah merahasiakan peristiwa keajaiban tersebut dan tidak memberi tahukan kepada puteranda Kanjeng Gusti Pangeran Adi Pati Anom, sehingga beliau tidak mengetahui bahwa yang berada di hadapannya itu adalah Raden Ajeng Handaya.

Setelah Kanjeng Gusti Pangeran Adipati Anom betul-betul jatuh cinta kepada Raden Ajeng Handaya dan ingin menikah dengan puteri tersebut, maka sesuai dengan kehendak Kanjeng Sunan Paku Buwana III, kemudian dilaksakanlah pernikahan antara Kanjeng Gusti Pangeran Adipati Anom dengan Raden Ajeng Handaya. Namun pada akhirnya Kanjeng Gusti Pangeran Adipati Anom mengetahui juga bahwa puteri yang menjadi pujaannya itu ternyata adalah Raden Handaya puteri dari Madura yang pernah ditolaknya pada waktu dulu. Akan tetapi dengan penampilan yang sungguh sangat berbeda, maka hati Kanjeng Pangeran Adipati Anom tetap jatuh cinta dan melangsungkan pernikahannya dengan penuh kebahagiaan. Kemudian dengan pernikahannya tersebut, maka Kanjeng Sunan Paku Buwana III memberikan gelar kepada Raden Ajeng Handaya dengan sebutan Raden Ayu Adipati Anom ( K. R. M. H. Yosodipuro: Wawancara. 5-5-1984).

Namun kebahagiaan tersebut tidak berlangsung lama, sebab setelah melahirkan putera pertamanya Raden Ayu Adipati Anom wafat. Tiga tahun kemudian Kanjeng Gusti Pangeran Adipati Anom naik tahta dan 
bergelar Kanjeng Sunan Paku Buwana IV. Karena Raden Ayu Adipati Anom telah wafat, maka untuk permaisuri beliau, Kanjeng Sunan Paku Buwana IV berkenan mengambil seorang puteri dari Madura lagi yaitu Raden Ajeng Sakaptinah yang masih merupakan adik kandung Raden Ayu Adipati Anom almarhum. Kemudian setelah berkedudukan sebagai permaisuri, maka Raden Ajeng Sakaptinah bergelar Kanjeng Ratu Kencana. Hal ini dibenarkan di dalam catatan sejarah ageng ing Karaton Surakarta yang mana disebutkan bahwa:

KangdjengSoesoehunanPakoeboewono IV garwane loro,

1. Raden Aju Adipati Anom, garwo sadoeroenge djumeneng Nata, ning terus seda.

2.Kangdjeng Ratoe Kentjana/Raji Raden Aju Adipati Anom.

(R.Ng. Wirapratama. Tt, p. 94).

Dengan demikian bisa diduga bahwa kecintaan Sunan Paku Buwana IV terhadap puteri darah Madura sangat kuat, di samping itu merupakan sebuah bukti bahwa dengan dipersuntingnya lagi puteri dari Madura itu, maka hubungan kekeluargaan antara Keraton Surakarta dengan Kadipaten Madura semakin erat. Oleh sebab itu nama Duradasih tercipta diperkirakan untuk mewujudkan rasa cinta Kanjeng Gusti Pangeran Adipati Anom yang sangat besar terhadap puteri darah Madura. Di dalam sebuah buku yang berjudul Sunan Sugih mengatakan bahwa:

Watawis tigang warsa saking jumeneng Nata, awit saking kepareng dalem badhe anambut silaningakrama ingkang kakarsakaken badhe kapundhut prameswari dalem punika ingkang rayi Bandara Raden Ayu Adipati Anom ingkang sampun swarga, nama Raden Ajeng Sakaptinah, atmajanipun Raden Adipati Cakraningrat, bupati ing Pamekasan Madura, dados nama ngarangulu (R.M. Soemantri Soemosapoetra. 1985. Sunan Sugih Babaran Ingkang Kaping III. p. 23 ).
Dari uraian tersebut di atas, maka nama Duradasih dapat disimpulkan bahwa nama itu terdiri dari dua kata yaitu dura dan dasih. Kata dura diambil dari Madura dan dasih dapat diartikan sebagai kasih atau cinta kasih. Hal ini dapat dimungkinkan bahwa seorang Adipati atau raja dapat menuangkan suatu ekspresi perasaannya melalui sebuah ungkapan ke dalam bentuk seni tari yaitu tari bedaya. Seperti telah dikatakan di depan bahwa bedaya adalah merupakan salah satu pusaka atribut kerajaan, yang menjadi kebanggaan serta salah satu unsur penegak kewibawaan raja, maka sebagai ekspresi budaya pada masa itu Bedaya Duradasih ini perlu diciptakan.

\section{Bedaya Duradasih sebagai Polarisasi Kehidupan Keraton Surakarta pada Masa Sunan Paku Buwana III-IV}

Sunan Paku Buwana IV adalah seorang raja dari Keraton Surakarta yang dinobatkan pada hari Senin Pahing tanggal 28 Zulhijah atau bulan Besar, tahun Jimakir 1714 Sinengkalan: Dadi Raja Sabdaning Rama. Pada saat itu tepat pada 29 September tahun 1788, Sinengkalan: Brahmana Hasta Amulang Raja, Wuku Kulawu Windu Hadi. Ketika dinobatkan sebagai raja, beliau baru berusia 20 tahun lebih 7 bulan ( Sunar Tri Suyanto. 1985. p. 24 ).

Walaupun masih muda usianya, ilmuilmu yang telah dikuasainya antara lain yaitu ilmu tentang ketatanegaraan, pemerintahan, pertanian, keprajuritan, dan di dalam bidang kesenian, terutama tentang kesusasteraan, karawitan dan seni tari. Ilmu-ilmu tersebut diajarkan kepada putera, cucu dan semua keturunannya. Ajaran-ajaran tersebut disampaikan dengan melalui bentuk tembang atau sekar, serta buku-buku dan juga disampaikan dengan secara lisan.

Salah satu ajaran dari kanjeng Sunan Paku Buwana IV yang sangat terkenal adalah Serat Wulangreh. Selain itu ada juga Serat Suluk Tembang Raras atau Serat Centhini, yang terdiri dari 12 jilid. Salah satu isinya yaitu meliputi tentang kesusasteraan, 
gending-gending, tari-tarian serta sekar atau Tembang Ageng, Tengahan dan Macapat serta pedalangan (Sunar Tri Suyanto. 1985, p. 79).

Dengan demikian Sunan Pakubuwana IV adalah seorang raja yang mempunyai jiwa seni yang sangat besar, sehingga tak dapat dipungkiri lagi bahwa pada masa pemerintahannya tentu saja kehidupan seni budaya sangat diperhatikan dan hidup serta berkembang dengan sangat subur. Hal ini sudah terbukti dengan diawalinya dari semenjak beliau masih bergelar sebagai Kanjeng Gusti Adipati Anom telah diciptakannya gending-gending serta tarian. Diantaranya adalah gending dan bedaya Duradasih, yang merupakan salah satu ekspresi budaya pada sat itu. Hal ini dikarenakan ungkapan ekspresi yang tercipta itu telah diilhami oleh suasana hati yang sedang jatuh cinta/gandrung/ kasmaran kepada puteri darah Madura. Dengan melihat ungkapan semacam itu, maka dapat dihubungkan dengan beberapa pendapat mengenai arti dari Duradasih. Pertama dikatakan bahwa Duradasih adalah dari kata Dura dan dasih, yang artinya adalah dura mengambil dari kata Madura dan dasih berarti abdi perempuan (S. Prawiroatmojo. 1988, p. 90). Jadi pendapat pertama ini mengatakan bahwa Duradasih merupakan penggabungan dari Madura dan dasih, yang artinya seorang abdi dalem perempuan dari Madura. Kemudian pendapat yang kedua, Duradasih disebutkan dengan nama Daradasih yang artinya ialah: Dara yaitu seorang dara atau gadis, sedangkan dasih di sini mempunyai arti kebahagiaan (Moelyono Sastronaryatmo. 1983. " Serat Pesindhen Bedhaya" p. 56). Sehingga Daradasih dapat berarti seorang dara atau gadis yang membawa kebahagiaan. Selanjutnya pendapat yang ketiga menyebutkan bahwa kata Duradasih ini disebut juga dengan kata Doradasih, yaitu dari kata Dora dan dasih, yang artinya dora adalah membohongi (dengan tujuan yang baik), dan dasih adalah merupakan cinta kasih (K. R. M. H. Yosodipuro: Wawancara 5-5-1984). Membohongi dalam pengertian ini ialah pada waktu Sunan Paku Buwana III berupaya untuk merubah wajah serta tabiat Raden Ajeng Handaya agar bisa menjadi menantunya demi kepentingan politik serta mempererat hubungan antara Madura dengan keraton Surakarta. Dengan demikian dapat dikatakan di sini bahwa kata Doradasih berarti membohongi untuk mendapatkan cinta kasih.

Dengan beberapa uraian tentang hal tersebut di atas, maka Bedaya Duradasih dapat pula disebut dengan nama Daradasih dan juga Doradasih. Hal ini seperti yang telah tertulis di dalam buku Weda Pratangga yaitu menyebutkan bahwa:

Ingkang Sinuwun Paku Buwana kaping IV, kajawi anganggit gendhing ugi iyasa lalangen dalem beksan kados ngandhap punika:

1. Beksan badhaya gendhing Daradasih, slendro pathet Manyura, gendhing kemanak gangsa lokananta. Daradasih wau katelah dipun serat: Doradasih, saweneh amastani: Duradasih, amargi pethikan saking lagunipun Sekar Ageng Duradasih iyasan dalem nalika dereng jumeneng Nata, taksih jumeneng Kanjeng Gusti Pangeran Adipati Anom. Panganggitipun amarengi ing dinten malem akat tanggal kaping 30 Dulkangidah, ing warsa Jumakir angka 1707.

2. Badhaya gendhing Ela-ela, gendhing gamelan raras pelog pathet nem. Yasan dalem sampun jumeneng Nata, panganggitipun amarengi ing warsa Alip, angka 1723.

3. Beksan Wireng, Gelas Alit, ingkang beksa cacah sekawan, gendhing Boyong.

(K.R.T. Warsodiningrat. 1979. Weda Pradangga, p. 58).

Kecuali keterangan yang telah disebutkan di atas, dalam sebuah buku yang berjudul R.M.Ng. Wignyahambeksa: Hasil Karyanya dan Pengabdiannya. Dikatakan pula bahwa tarian yang berasal dari jaman pemerintahan Sunan Paku Buwana IV disebutkan juga tari Panji 
Sepuh, yaitu jenis tarian tunggal dan tari Panji Enem, ditarikan oleh dua orang penari lakilaki. (Sukirman Dharmamulya. 1981/1982. R. M. Ng. Wignyahambeksa: Hasil Karyanya dan Pengabdiannya, p. 8).

Di dalam budaya Keraton Surakarta, mengatakan bahwa untuk menciptakan sebuah tari baik itu tari bedaya maupun serimpi dan juga tari yang lain, maka iringannya diciptakan terlebih dahulu dari pada tarinya. Kemudian untuk selanjutnya nama dari pada beksannya atau tarinya diambilkan dari nama gending pengiringnya (Pakoe Boewono XII. 1992. “ Seminar Kebudayaan Posisi Kraton di Tengah Perubahan Zaman"). Demikian pula halnya dengan Bedaya Duradasih, sehingga ungkapan ekspresinya cenderung lebih nampak dengan jelas melalui kalimat-kalimat yang terdapat di dalam gerongannya. Misalnya: "Duradasih kadi sinawung asmara, yang artinya kurang lebih ialah: bersama puteri darah Madura berpadu dalam kasih. Kemudian di dalam kalimat yang lain yaitu misalnya: "Hanrus gandaning kusuma na ulating dasih, yang artinya yaitu: bagaikan bunga alangkah bahagiaku mencium keharumanmu (Martopangrawit. 1975. "Titi Laras Gending dan Sindenan Bedaya - Srimpi Kraton Surakarta", p. 53-56).

Tari Bedaya di dalam bentuk penyajiannya, pada umumnya selalu disajikan dalam polapola gerak yang sangat simbolis, demikian pula gerak-gerak tari yang terdapat di dalam tari Bedaya Duradasih. Dengan penyajian yang seperti tersebut di atas, maka sangat sulit untuk menunjuk secara tegas tentang gerak-gerak tari yang mengungkapkan ekspresi dan mempunyai makna. Dengan melalui pengamatan yang cukup lama serta mempelajari secara mendetail tentang gerak tari Bedaya Duradasih tersebut, maka secara simbolis dapat dilihat melalui bentuk koreografi tari bedaya tersebut. Pada gerakgerak tertentu yang terdapat yang terdapat di dalam sebuah pola lantai, dapat diperkirakan sebagai penggambaran dalam perjalanan lewat sungai dengan menggunakan perahu dayung, sebab di dalam susunan tari bedaya yang lain pola-pola gerak tari seperti tersebut di atas hampir tidak ada. Hal ini sesuai dengan keadaan pada masa pemerintahan Sunan Paku Buwana III--IV, yang mana telah disebutkan bahwa semua hubungan lalu lintas antara Surakarta dengan Madura dicapai melalui sungai dengan menggunakan kapal atau perahu dayung. Kemudian apabila dilihat pada pola lantai yang lain ada diantaranya gerak tari yang dilakukan oleh dua orang penari yaitu penari batak dan endel ajeg yang seolaholah menggambarkan sepasang kekasih yang sedang memadu cinta, sedangkan penaripenariyang lainya bergerak seakan-akan menggambarkan pepohonan yang tumbuh di sebuah taman dan bergoyang-goyang tertiup angin. Dengan melihat koreografi seperti itu, maka sangat dimungkinkan suasana seperti itu sama dengan situasi di kerajaan pada waktu itu. Terutama keadaan di dalam taman yang penuh dengan suasana damai serta penuh cinta kasih.

Seperti yang telah diuraikan sebelumnya bahwa Sunan Paku Buwana IV adalah seorang yang mempunyai jiwa seni yang sangat besar, hal ini juga terbukti pada saat pernikahan beliau dengan Raden Ajeng Sakaptinah yaitu pada hari Rabu wage, tanggal 16 Zulhijah (Besar), tahun Jimawal, 1717, Sinengkalan : Pandita Luwih Kalokeng Rat atau tanggal 17 Agustus 1791, Sinengkalan: Janma Sanga Anabda Tunggal, Wuku Kulawu, Windu Kuntara (Sunar Tri Suyanto. 1985, p. 25). Di dalam menyambut pernikahan tersebut, Keraton Surakarta diadakan pesta seni secara besarbesaran, baik panggung-panggung terbuka maupun langen budaya, yang semuanya dilaksanakan selama empat puluh hari empat puluh malam. Selain peristiwa seperti itu, pesta kesenian semacam ini juga dilaksanakan pada saat-saat memperingati hari kelahiran serta hari ulang tahun Sunan Paku Buwana IV. Kemudian hal semacam itu juga dilaksanakan pada saat memperingati hari kelahiran serta hari ulang tahun permaisuri dan harihari kelahiran maupun ulang tahun putera mahkota. Pada setiap peringatan hari besar 
atau hari raya pun juga diselenggarakan pesta seni secara besar-besaran. Dengan begitu sangat dimungkinkan bahwa Bedaya Duradasih pada saat pemerintahan Sunan Paku Buwana III--IV merupakan salah satu ekspresi budaya yang hidup dan berkembang pada saat itu.

\section{Urutan dan Ragam Tari Bedaya Duradasih}

1. Gendhing Duradasih Laras Slendro Pathet Manyura

1). Mangenjali (Sembahan)

2). Pendhapan Kebyok

3). Pendhapan Ukel Sampur-Sendhi gerak

4). Laras Duradasih

5). Pendhapan Kebyok

6). Pendhapan Ukel Sampur

7). Laras Duradasih

8). Pendhapan Asta

9). Pendhapan Ukel Sampur

10). Pendhapan Asta

11). Pendhapan Ukel Sampur

12). Laras Duradasih

13). Pendhapan Asta

15). Pendhapan Ukel Sampur

16). Laras Duradasih

17). Pendhapan Asta

18). Pendhapan Ukel Sampur

19). Lung Manglung

20). Ngglangsur

21). Panahan

22). Lung Manglung

23). Ngglangsur

24). Panahan

25). Lung Manglung - Sendhi gerak

26). Lung Manglung

27). Ngglangsur

28). Pendhapan Asta Separo

29). Nikelwarti

2. Ndawah Ketawang Kinanthi Duradasih

1). Mangenjali

2). Pendhapan Ridong Sampur

3). Laras Duradasih

4). Ngembat Nglayang

5). Nglayang-Nglayang
6). Pendhapan Ridong Sampur

7). Laras Duradasih - Sendhi Srisig

8). Nikelwarti

9). Kebyok-an Sampur

10). Atrap Pundak

11). Ngglangsur

12). Kebyok-an Sampur

13). Atrap Pundak

14). Ngglangsur

15). Rimong Menjangan Ranggah

16). Enjer Ridong Sampur

17). Nikelwarti

18). Ngunus

19). Perangan

20). Memasukkan Pistol

21). Lembehan Separo

22). Pendhapan Utuh

23). Nikelwarti

\section{Penutup}

Bedaya tentulah mempunyai kemungkinan yang cukup besar untuk mampu mencerminkan suatu warna lingkungan yang khas, termasuk dalam segi filosofis, norma dan etika, maupun faham-faham yang berkembang di dalam lingkungan kehidupannya. Karena lingkungan Keraton dengan dengan raja sebagai pewaris kebudayaan, mewarisi semua tatanan dan faham-faham tersebut secara turun temurun, dimana seluruhnyanya itu amat berpengaruh terhadap semua aktifitas hidup lingkungannya. Maka fungsi dan kedudukan tari bedaya itu sendiri secara umum tidak akan lepas dari fungsi dan kedudukannya sebagai pusaka sang raja.

Seperti yang telah diuraikan di muka, bahwa pada umumnya nama dari tari bedaya di Surakarta itu mengambil dari nama gending yang mengiringinya. Tidak seperti halnya dengan tari bedaya di Yogyakarta yang biasanya mengambil dari isi ceriteranya, sebab pada umumnya tari bedaya di Yogyakarta membawakan suatu ceritera. Namun nama Duradasih yang dipakai sebagai judul dari sebuah tari bedaya di Surakarta pada masa pemerintahan Sunan Pakubuwana III-IV ini 
adalah merupakan peristiwa yang melatar belakangi sebuah penciptaan tari bedaya pada masa itu.

Secara simbolis dapat dilihat melalui bentuk koreografinya, maka tari Bedaya Duradasih tersebut dapat diinterpretasikan merupakan gambaran suatu percintaan. Hal ini dapat dilihat melalui beberapa ragam gerak tarinya dan juga pada pola lantai yang terdapat di dalamnya. Karena pada masa itu terjalin dengan baik hubungan antara Keraton Surakarta dan Kadipaten Madura, maka dengan demikian simbol hubungan tersebut diekspresikan melalui sebuah bentuk tari bedaya yang kemudian disebut dngan Bedaya Duradasih.

Dari beberapa uraian di atas, maka Bedaya Duradasih ternyata tidak hanya sekedar mengambil dari nama gendingnya saja, tetapi gerak-gerak tarinya ataupun juga koreografi yang terdapat di dalamnya merupakan penggambaran dari ekspresi jiwa seseorang yang dituangkan ke dalam sebuah bentuk tari yaitu Bedaya Duradasih.

\section{Ucapan Terima Kasih}

Assalamualaikum. Wr. Wb.

Dengan mengucapkan syukur alhamdulilah makalah yang berjudul "Bedaya Duradasih Sebuah Ekspresi Budaya pada Masa Sunan Pakubuwana III-IV di Keraton Surakarta dapat diselesaikan. Makalah ini dapat terwujud tentunya karena bantuan dari berbagai pihak. Oleh karena itu pada kesempatan ini diucapkan terima kasih kepada:

1. Nara sumber K.R.M.H. Yosodipuro (Almarhum), dan Sutjiati Doko Suhardjo (Almarhum) yang telah memberikan datadata yang sangat penting untuk membantu terwujudnya tulisan ini.

2. Ketua Jurusan tari yang telah mendorong dan memotivasi dalam menuliskan hasil penelitian ke dalam jurnal.

3. Dekan Fakultas Seni Pertunjukan yang telah mendorong penulis untuk menulis
Jurnal terkait dengan persyaratan Tri Darma Perguruan Tinggi bagi Dosen.

4. Editor jurnal DTR yang telah bersedia memberikan masukan dengan mereview tulisan ini.

5. Seluruh pengelola Jurnal DTR yang telah memberikan kesempatan untuk dapat memasukkan tulisan ini ke dalam Jurnal DTR.

6. Ketua LPPM ISI Yogyakarta yang telah menerima proposal penelitian yang hasilnya dapat diwujudkan dalam bentuk jurnal di DTR sebagai salah satu luaran dari penelitian.

Akhir kata semoga tulisan sederhana ini dapat memberikan sumbangan pengetahuan yang terkait dengan Bedhaya Doradasi di Kasunanan Surakarta masa PB III-IV. Tentu saja tulisan ini masih jauh dari sempurna. Oleh karena itu kritik, saran dan masukan sangat kami harapkan untuk perbaikan dari tulisan ini. Terima kasih apabila ada kata yang kurang berkenan mohon maaf sedalamdalamnya.

Wassalamualaikum. Wr. Wb.

Yogyakarta, 22 September 2021

Penulis

\section{Kepustakaan}

Arikunto, Suharsimi. 1993. Manajemen Penelitian. Jakarta: PT Rineka Cipta

Babad Tanah Jawi. 1980. Terjemahan Sudibyo Z. H. Jakarta : Departemen Pendidikan Dan Kebudayaan Proyek Penerbitan Buku Sastra Indonesia dan Daerah

Boewono XII, Pakoe. 1992. "Seminar Kebudayaan Posisi Kraton di Tengah Perubahan Zaman". Yogyakarta: Persatuan Wartawan Indonesia Yogyakarta.

Cassirer, Erns. 1987. Manusia dan Kebudayaan: Sebuah Esei Tentang Manusia. Terjemahan Alois A. Nugroho. Jakarta: Gramedia. Dharmamulya, Sukirman. 1981/1982. R. M. Ng. Wignyahambeksa: Hasil Karyanya dan Pengabdiannya. Jakarta: Dept. P dan 
K Proyek Inventarisasi dan Dokumentasi Sejarah Nasional.

Duverger, Maurice. 1985. Sosiologi politik.

Terjemahan Daniel Dhakidae. Jakarta: CV Rajawali.

Duvignaud, Jean. 1988. "Sosiologi Seni". Terjemahan Y. Sumandiya Hadi dan Christianto Rich. Yogyakarta: ISI Yogyakarta.

Haviland, William A, 1985. Antropologi Jilid 2. Terjemahan Soekadijo. Jakarta: Erlangga. Heine-Geldern, Robert. 1982. Konsepsi tentang Negara \& Kedudukan Raja di Asia Tenggara. Terjemahan Deliar Noer. Jakarta: CV Rajawali

Herusatoto, Budiono. 1987. Simbolisme Dalam Budaya Jawa. Yogyakarta: PT Hanindita. Kusmayati, Hermien. 1988. "Bedaya di

Pura Paku Alaman Pembentukan dan Perkembangannya 1909-1987" Sebuah Tesis untuk memenuhi sebagian persyaratan untuk mencapai derajat Sarjana S-2. Program Studi Sejarah Jurusan Ilmu-Ilmu Humaniora. Universitas Gdjah Mada.

Martopangrawit. 1975. "Titi Laras Gending dan Sindenan Bedaya - Srimpi Kraton Surakarta". Surakarta: ASKI Departemen $\mathrm{P}$ dan $\mathrm{K}$.

Moertono, Soemarsaid. 1985. Negara dan Usaha Bina Negara di Jawa Masa Lampau. Jakarta: Yayasan Obor Indonesia.

Pujaswara, Bambang. 1982. "Studi Analisa Konsep Estesis Koreografis Tari Bedhaya Lambangsari". Skripsi yang diajukan untuk gelar Seniman Seni Tari. Yogyakarta: Akademi Seni Tari Indonesia Yogyakarta.

Sastronaryatmo, Moelyono. 1083. "Serat Pesindhen Badhaya". Alih Bahasa. Jakarta: Departemen Pendidikan dan Kebudayaan. Sedyawati, Edi. 1981. Pertumbuhan Seni Pertunjukan. Jakarta: Sinar Harapan. 1984. Tari: Tinjauan dari berbagai Segi. Jakarta: Pustaka Jaya.

Soedarsono. 1989. "Raja Jawa dan Seni: Sebuah Contoh Pengaruh Konsepsi
Kekuasaan Raja Terhadap Konsepsi Seni Pertunjukan". Sebuah caramah dalam sarasehan Javanologi pada hari Senin legi tanggal 25 September 1989 di Jl. Brigjen Katamso 139 Yogyakarta. Yogyakarta: Proyek Penelitian dan Pengkajian Kebudayaan Nusantara, Bagian Jawa, Direktorat Jendral Kebudayaan, Departemen Pendidikan dan Kebudayaan.

Soemosapoetro, Soemantri. 1985. Sunan Sugih. Babaran Ingkang Kaping III. Surakarta: Paguyuban Darah Dalem PB V.

Soeratman, Darsiti. 1989. Kehidupan Dunia Kraton Surakarta. 1830-1939. Yogyakarta: Tamansiswa.

Soerdjodiningrat, P. A. 1934. Babad Lan Mekaring Djoged Djawi. Jogjakarta: Kolf Boening.

Suharti. Theresia. 1990. "Tari di Mangkunegaran: Suatu Pengaruh Bentuk dan Gaya Dalam Dimensi Kultural, 19161988". Sebuah Tesis untuk Memenuhi sebagian persyaratan untuk mencapai derajat Sarjana S-2, Program Studi Sejarah Jurusan Ilmu-Ilmu Humaniora Univesitas Gadjah Mada.

Surono. 1982. "Punika Serat Kapranatan Nalika Jaman Nagari Dalem Ing Kartasura, Kala Ing Tahun 1655". Transliterasi. Surakarta: Perpustakaan Wreksa Pustaka Mangkunegaran.

Suyanto, Sunar Tri. 1985. Ingkang Sinuhun Kanjeng Susuhunan Paku Buwana IV Beserta Ajaran-ajarannya. Solo: Tiga Serangkai

Warsodiningrat. K. R. T. 1979. Weda Pradangga. Surakarta: SMKI

Wirapratama, R.Ng.Tt.Transliterasi.Surakarta: Perpustakaan Kraton Surakarta.

\section{Informan}

1. K.R.M.H. Yosodipuro (Almarhum)

2. Sutjiati Djoko Suhardjo (Almarhum)

3. S. Ngaliman (Almarhum)

4. Sri Mulyani (Almarhum) 